\title{
"EL HOMBRE SIRENA" DE SAMANTA SCHWEBLIN, O LOS ELEMENTOS NEOFANTÁSTICOS EN LA CONTEMPORANEIDAD
}

\author{
Jorge Antonio Sánchez Rivera \\ Boston University \\ jasr@bu.edu
}

Resumen: Samanta Schweblin se ha consagrado como una de las escritoras contemporáneas más leídas y sus cuentos han sido abordados desde diversas ópticas teóricas que incluyen lo fantástico o lo siniestro. Sin embargo, algunos de sus relatos se pueden analizar desde la poética de lo neofantástico porque estos difieren de otros géneros en su visión, intención y modo de operar. Varios de sus relatos utilizan una metáfora epistemológica para explorar el propósito principal de la ficción neofantástica: el ser humano contemporáneo y su mundo. Precisamente, Schweblin logra entrever dentro de sus cuentos situaciones que atañen a lo que Giorgio Agamben define como "lo contemporáneo". Así, pues, este artículo examinará el cuento "El hombre sirena" para demostrar que la autora se vale de la poética de lo neofantástico para explorar y profundizar en la sociedad contemporánea y en conceptos como el androcentrismo, el falogocentrismo y el deseo de libertad de la mujer.

Palabras clave: neofantástico, metáfora, contemporáneo, androcentrismo, identidad de género

\section{SAMANTA SCHWEBLIN'S "EL HOMBRE SIRENA" AS REPRESENTATION OF THE NEO-FANTASTICAL ELEMENTS IN CONTEMPORANEITY}

\begin{abstract}
Samanta Schweblin has established herself as one of the most widely read contemporary authors. Her short stories have been approached from various theoretical perspectives that include the fantastic or the uncanny. However, some of her short stories can be analyzed through the neofantastic poetic because they differ from other genres in their vision, intention and modus operandi. Her short stories use an epistemological metaphor to explore the objective of neo-fantastic fiction: the contemporary human being and his world. In fact, with her short stories Schweblin manages to glimpse at situations that concern what Giorgio Agamben defines as "the contemporary". Thus, this article will examine the story "El hombre sirena" (The Merman) to demonstrate that the author uses the neo-fantastic to explore and delve into contemporary society as well as into concepts such as androcentrism, phallogocentrism and the desire for freedom of woman.
\end{abstract}

Keywords: neo-fantastic, metaphor, contemporary, androcentrism, genre identity

DOI: https://doi.org/10.24029/lejana.2020.14.935 
Recibido: el 28 de agosto de 2020

Aceptado: el 10 de diciembre de 2020

Publicado: el 26 de febrero de 2021 
Samanta Schweblin es una escritora argentina que ha obtenido un lugar consagrado en la literatura hispanoamericana actual ${ }^{1}$ y que se inscribe dentro de una tradición literaria reconocida a través de relatos que exploran el género fantástico. La autora dialoga con el canon del género fantástico hispanoamericano, el cual posee autores renombrados como Jorge Luis Borges, Adolfo Bioy Casares, Julio Cortázar, Rosario Ferré o Silvina Ocampo. A pesar de que Schweblin escribe en actualidad, con temas y sucesos que atañen a la contemporaneidad (Sánchez Rivera, 2020: 118), esta, a su vez, mantiene una distancia suficiente en relación con la historia literaria para dialogar con el pasado — con la tradición literaria - mientras indaga en situaciones del presente. Dicha capacidad de explorar y profundizar en temas o situaciones que corresponden al presente sin ignorar las ideas o sucesos de otros tiempos es una de las características del ser humano contemporáneo según el filósofo italiano Giorgio Agamben. Para sostener dicho diálogo, la autora argentina se vale en algunos de sus cuentos de la poética de lo neofantástico y aborda eventos o enigmas de la contemporaneidad que requieren del lenguaje renovado de lo neofantástico para expresar lo que resulta incomunicable con nuestro conocimiento lógico-científico. Al tomar el planteamiento anterior como punto de partida, en este artículo se analizará cómo la escritora utiliza el lenguaje metafórico de lo neofantástico para explorar temas o situaciones que atañen al ser humano contemporáneo, a su sociedad y a la tradición literaria. Específicamente, examinaré el cuento "El hombre sirena", contenido en la colección Pájaros en la boca y otros cuentos (2017), y, basándome en los planteamientos teóricos de Jaime Alazraki, Giorgio Agamben, Pierre Bourdieu, Rita Segato y Judith Butler, demostraré cómo la imagen del hombre sirena critica la tradición simbólico-literaria androcentrista y el pensamiento falogocentrista en cuanto a la identidad de género. Asimismo, argumentaré que la metáfora neofantástica del hombre sirena contiene varias interpretaciones y que una de ellas es el deseo de libertad de la mujer ante la sociedad androcentrista, una situación que apela al ser humano, la sociedad y el mundo contemporáneos.

Primeramente, habría que aclarar que no todos los escritores ni sus obras mantienen esa cualidad de "lo contemporáneo" a pesar del tiempo. Según Agamben, la capacidad de profundizar en el presente mediante el diálogo con otros tiempos es un rasgo que distingue al escritor contemporáneo:

Pertenece en verdad a su tiempo, es en verdad contemporáneo, aquel que no coincide a la perfección con este ni se adecua a sus pretensiones [...]; pero, justamente por esto, a partir de ese alejamiento y ese anacronismo, es más capaz que los otros de percibir y aferrar su tiempo. [...] La contemporaneidad es, pues, una relación singular con el propio tiempo, que adhiere a este y, a la vez, toma su distancia; más exactamente, es esa relación con el tiempo que adhiere a este a través de un desfase y un anacronismo. (Agamben, 2011: 18-19)

\footnotetext{
${ }^{1}$ Quiero destacar a tres críticos que han notado el valor literario de Schweblin: Elsa Drucaroff, Agustín Prado Alvarado y Ana Gallego Cuiñas. La primera ha declarado que Schweblin es quizás la mejor cuentista de su generación, en otras palabras, de la segunda generación de la postdictadura en Argentina (2011: 120, 213-215); mientras que Prado Alvarado ha expresado: "Samanta Schweblin, no solamente es una de las mejores cuentistas del orbe hispano, sino que muchos de sus cuentos, realmente magistrales, los podemos considerar como parte de los nuevos derroteros dentro de la tradición fantástica hispanoamericana" (2017: 15); y Gallego Cuiñas menciona la consagración de la escritora dentro de los escritores del siglo XXI (2018: 11) y su alcance en el ámbito internacional (2020: 75-76).
} 
A esta descripción, el filósofo añade que el artista contemporáneo contempla o mira fijamente a su propio tiempo (presente), mas no para observar sus "luces", sino su componente oscuro, sus tinieblas; es el autor quien escribe sobre la "oscuridad" del presente (Agamben, 2011: 21). Luego arguye que dicha característica de observación es una habilidad singular, pues "implica una actividad y una habilidad particulares que, en nuestro caso, equivalen a neutralizar las luces provienentes de la época para descubrir su tiniebla, su especial oscuridad, que no es, sin embargo, separable de esas luces", y agrega: "Puede llamarse contemporáneo sólo aquel que no se deja cegar por las luces del siglo y es capaz de distinguir en ellas la parte de la sombra, su Íntima oscuridad" (Agamben, 2011: 22). Cabe añadir que un escritor contemporáneo, dentro de esa oscuridad de su tiempo a la que se fija su mirada, entrevé destellos de luz que no toda persona reconoce fácilmente, son seres "raros", lo que "significa ser capaces, no sólo de mantener la mirada fija en la oscuridad de la época, sino también de percibir en esa oscuridad una luz que, dirigida hacia nosotros, se nos aleja infinitamente. [...] Y nos permite, además, reconocer en la tiniebla del presente la luz que, sin poder alcanzarnos jamás, está permanentemente en viaje hacia nosotros" (Agamben, 2011: 23-24). De manera que solo algunos escritores pueden entrever dentro de las tinieblas del presente las ideas, situaciones o eventos que pasan inadvertidos para otras personas. Estos establecen un diálogo con el pasado y el futuro, pues evocan, rememoran y revitalizan aquello que se ha declarado muerto o parte del pretérito (Agamben, 2011:26).

Ciertamente, Schweblin forma parte de esos autores que Agamben considera contemporáneos, porque reflexiona y escribe sobre la actualidad mientras se dista de esta para dialogar con otros tiempos, o sea, con la tradición literaria del género fantástico en Hispanoamérica $^{2}$ y con los temas o situaciones que continuarán preocupando al humano en el futuro próximo: la violencia doméstica, la pedofilia, las nuevas tecnologías, el machismo, el campo y los nuevos retos que enfrenta, la identidad de género, entre otros (Sánchez Rivera, 2020: 119120). Ahora bien, como mencioné anteriormente, para examinar y ahondar en esos sucesos, entes y situaciones que conciernen al ser humano contemporáneo y su mundo, la autora bonaerense utiliza elementos neofantásticos en gran parte de su cuentística. ${ }^{3}$ La poética de lo neofantástico, desarrollada por Jaime Alazraki para estudiar los relatos de Julio Cortázar, sirve para explorar y expresar mediante una metáfora epistemológica sucesos que resultan incomunicables en el lenguaje común. Conviene explicar esta poética, su diferencia frente al fantástico tradicional y el lenguaje metafórico del que se vale para aproximar al lector a situaciones inexpresables por el lenguaje común del ser humano.

Lo fantástico nuevo, a diferencia del género tradicional del siglo XIX, no se propone estremecer ni horrorizar con un evento sobrenatural, sino que expande la realidad acostumbrada y permite la entrada de un orden alterno, sin estos negarse (Alazraki, 1983: 35). Ciertamente, dentro de la ficción neofantástica, lo insólito se suscita desde la cotidianeidad, y tal evento "prescinde del miedo, porque lo otro emerge de una nueva postulación de la realidad, de una nueva percepción

\footnotetext{
${ }^{2}$ Diversos críticos han estudiado las tangencias, ecos o diálogos entre los relatos schweblianos y la tradición fantástica hispanoamericana, conviene resaltar los textos de Flavio Garcia y Julia Livellara Abrile.

${ }^{3}$ Petra Báder, Agustín Prado Alvarado, Jorge Antonio Sánchez Rivera o Julia Livellara Abrile son varios de los críticos que señalan que algunos cuentos schweblianos pueden estudiarse desde el prisma de lo neofantástico.
} 
del mundo, que modifica la organización del relato [y] su funcionamiento" (Alazraki, 1983: 28; cursivas en el original). Alazraki abunda sobre su definición de lo neofantástico:

Desde el comienzo mismo del relato, la escala realista se yuxtapone a la escala fantástica, cada una gobernada por una clave diferente [...] en casi toda la ficción neofantástica, no hay un proceso gradual de presentación de la realidad para finalmente abrir en ella una fisura de irrealidad [...] el escritor de lo neofantástico otorga igual validez y verosimilitud a los dos órdenes, y sin ninguna dificultad se mueve con igual libertad y sosiego en ambos. (Alazraki, 1994: 69-70)

Por consiguiente, se comprende que tanto la visión como la intención del texto neofantástico difieren del género fantástico tradicional. ${ }^{4}$ También el modus operandi del cuento neofantástico es distinto, pues, como se lee en la cita anterior, no hay en estos cuentos una presentación de la realidad conocida por los lectores para gradualmente socavarla con un evento sobrenatural que desestabiliza esa realidad. Por el contrario, en el texto neofantástico, la realidad conocida y el nuevo orden se aúnan sin negarse, sin violarse, sin causar un detente de lectura (Alazraki, 2010: 796).

Asimismo conviene señalar que el elemento neofantástico se proyecta a través de metáforas epistemológicas que intentan aproximar al lenguaje un sentido incomunicable del relato y que ayudan a "aprehender un orden que escapa a nuestra lógica racional con la cual habitualmente medimos la realidad o irrealidad de las cosas" (Alazraki, 1983: 35). Estas metáforas no admiten interpretaciones unívocas de lo que sustituyen en el texto: contiene un tenor, o la parte de la imagen que se busca definir o describir, y un vehículo, o la parte de la imagen que define o describe, por comparación, al tenor de la metáfora. La comparación establece una relación en la que tenor y vehículo se reconocen, y que se llamaría "base" (Alazraki, 1983: 38-39). La base, en todo caso, "alcanza una apertura" y, dentro del espacio limitado que abre la relación entre tenor y vehículo, "entra un número ilimitado de posibles interpretaciones [...] y en esa metáfora reconocemos una dimensión ontológica que trasciende al personaje mismo para hacerse experiencia de cada lector" (Alazraki, 1983: 39-40). Por lo tanto, dentro de la apertura que se establece entre el tenor y el vehículo de las metáforas neofantásticas cabría una miríada de interpretaciones que dependen de los lectores y de su experiencia durante la lectura; de ahí que las metáforas eludan la univocidad interpretativa. De esta forma, lo neofantástico explora y profundiza en el ser humano y su experiencia en el mundo, pues dentro de la ficción neofantástica, el único objeto ambiguo y enigmático es el propio ser humano, y no otros seres maravillosos. Estos textos se aproximan, por ejemplo, al inconsciente humano, a los entes extraños que moran en la llamada realidad, al avance exponencial de la tecnología o a las relaciones humanas. En este sentido, las metáforas connotan

\footnotetext{
${ }^{4}$ Cabe citar a Alazraki para dar cuenta de su explicación sobre la visión e intención del cuento neofantástico: "Por su visión, porque si lo fantástico asume la solidez del mundo real [...] lo neofantástico asume el mundo real como una máscara, como un tapujo que oculta una segunda realidad que es el verdadero destinatario de la narración neofantástica. La primera se propone abrir una «fisura» o «rajadura» en una superficie sólida e inmutable; para la segunda, en cambio, la realidad es [...] una esponja, un queso gruyère, una superficie llena de agujeros como un colador y desde cuyos orificios se podía atisbar, como en un fogonazo, esa otra realidad [...]. En lo que toca a la intención, el empeño del relato fantástico dirigido a provocar un miedo en el lector, un terror durante el cual trastabillan sus supuestos lógicos, no se da en el cuento neofantástico" (Alazraki, 2010: 794).
} 
los aspectos de la condición humana y apuntan a situaciones que permanecen ignotas para cualquier persona y que el ser o escritor contemporáneo puede inteligir y traducir mediante sus narraciones. ${ }^{5}$

Precisamente en relatos como "Conservas", "Mariposas", "Pájaros en la boca", "Matar a un perro" o "En la estepa" de Samanta Schweblin se pueden percibir estas metáforas neofantásticas que proyectan y expresan situaciones o entes inexpresables a través del lenguaje común y que indagan en el ser humano y su mundo. ${ }^{6}$ Sin embargo, conviene analizar el cuento "El hombre sirena" para demostrar cómo dichas metáforas apelan a la contemporaneidad y permiten entrever varios tenores que ahondan en la experiencia de mundo de los lectores actuales a la vez que establecen un diálogo con el canon de la literatura fantástica de Hispanoamérica y con los temas que figuran en el presente y futuro próximo del ser humano.

\section{"El hombre sirena" ante la tradición simbólico-literaria y la identidad de género}

En el cuento breve "El hombre sirena", una mujer narra en primera persona el momento en que se encuentra con un hombre sirena en el muelle cerca del bar donde bebía café mientras esperaba por su hermano. Ella ve la columna de hormigón donde está sentado el hombre sirena, determina ir hasta allá, se acerca y conversa con él. Habla de su madre, luego de su hermano Daniel y su obstinación en controlarla a ella, quien narra, pues este quiere saber dónde está, con quién habla, qué hace, prácticamente todo lo que acontece en su vida. Aun mientras conversan, la protagonista espera a que el hermano la busque tal como supuestamente habían quedado. Entonces, la narradora le habla de la condición de salud que padece la madre y, por último, conversan en torno a una posible cita posterior entre el hombre sirena y ella. Estos se besan y la narradora se percata de que, después de esa experiencia, nada seguiría igual en su vida. Daniel llega y la busca en el bar; ella lo ve y baja del hormigón para encontrarse con él. Este le dice que es tarde y que el médico los mataría. La narradora trata de desafiar a Daniel, mas cede ante la imposición de su hermano y observa cómo el hombre sirena se despide de ella, quien piensa en que, al otro día, ese ser estaría allí esperándola.

Lo primero que debo comentar es que la poética de lo neofantástico funciona como una herramienta efectiva para analizar el cuento, pues en la narración se advierte que la escala realista y la fantástica se aúnan sin negarse; la llamada realidad y el ente fantástico forman parte de un mismo orden. Asimismo, desde la primera oración se demuestra que la visión, intención y el modus operandi de este relato distan del fantástico tradicional:

Estoy sentada en el bar del puerto, esperando a Daniel, cuando veo al hombre sirena mirarme desde el muelle. Está sobre la primera columna de hormigón, donde el agua todavía no llega a la playa, a unos cincuenta metros. Tardo en reconocerlo, en entender qué es exactamente, tan hombre de la

\footnotetext{
${ }^{5}$ Es fundamental subrayar en la diferencia entre el género fantástico tradicional y el neofantástico porque: “Once this distinction has been made, we have not only a new label but a more effective critical tool for understanding these fictions that [...] both accept and reject all interpretations. Sometimes these interpretations [...] tell us more about the interpreter than about the text being interpreted" (Alazraki, 1999: 12).

${ }^{6}$ Remito al lector interesado al texto Elementos neofantásticos en la obra narrativa breve de Julio Cortázar y Samanta Schweblin que se encuentra en la bibliografía de este trabajo.
} 
cintura para arriba, tan sirena de la cintura para abajo. Mira hacia un lado, después tranquilamente hacia el otro, y al fin vuelve a mirar hacia acá. (Schweblin, 2017: 99) ${ }^{7}$

Se ve, por un lado, que la intención de este relato y del elemento neofantástico (el hombre sirena) no es sorprender, estremecer ni horrorizar al lector ni al personaje principal. Por otro lado, se observa que no hay un proceso de presentación de la realidad conocida para luego socavarla con un evento sobrenatural que deja en duda al lector sobre las leyes que imperan en ese mundo, sino que ambos órdenes (el reconocido y el sobrenatural o maravilloso) conviven en armonía. De modo que la visión, intención y el modus operandi del relato apuntan a la poética de lo neofantástico más que al fantástico tradicional. No obstante, faltaría analizar la metáfora neofantástica del hombre sirena para dilucidar los silencios u omisiones que la ficción contiene. ${ }^{8}$

En definitiva, el hombre sirena es una imagen de suma importancia en el cuento porque rompe la convención tradicional de lo que es una sirena, pues como menciona Paula C. Garrido, "La sirena, criatura que pertenece a la mitología griega, es una creación literaria por antonomasia cuya representación se encuentra altamente codificada. Aquí [en «El hombre sirena»] es tomada como punto de partida para transgredir la convención" (Garrido, 2014: 177). Ciertamente, basta leer lo que registran dos diccionarios de símbolos sobre la sirena para notar que la metáfora del hombre sirena hace una ruptura con la representación que la tradición literaria ha perpetuado en el imaginario colectivo: "mitad mujer, mitad pez; divinidad de las aguas" (Cooper, 1978: 64; traducción propia); "Figura simbólica que aparece bajo dos aspectos principales, como mujerpájaro o como mujer-pez" (Cirlot, 1992: 415). Aun la narradora del cuento dice: "Contra la idea que se tiene de las sirenas, hermosas y bronceadas, este no solo es del otro sexo sino que es bastante pálido" (Schweblin, 2017: 99). Así pues, podría interpretarse que la metáfora del hombre sirena implica también una ruptura contra el sistema ideológico y literario masculino que ha determinado y regido la imagen de la sirena como un ser mitológico o como un símbolo designado a la mujer. Si se remembran las palabras de Pierre Bourdieu sobre la dominación masculina en el orden social del mundo y en los sistemas perceptivos, de pensamiento y acción del ser humano: "el principio masculino aparece como la medida de todo" (Bourdieu, 2000: 27-28); entonces se comprende que la visión androcéntrica sea la que haya imperado sobre la imagen de la sirena como un ser únicamente femenino dentro de la tradición mitológica y literaria. Sobre esa visión androcéntrica que no necesita justificación para existir Bourdieu comenta:

\footnotetext{
${ }^{7}$ Este inicio en que el elemento fantástico nuevo se aúna a la llamada realidad sin ambos negarse y sin horrorizar o estremecer al lector o al personaje principal remite al cuento "Axolotl", de Julio Cortázar, cuya historia también muestra el elemento neofantástico desde las primeras líneas y con la misma cotidianeidad con que se lee la aparición del hombre sirena. Este efecto, como he aludido, explicita claramente la diferencia o distancia entre lo neofantástico y lo fantástico tradicional. Remito al lector interesado a la edición a cargo de Jaime Alazraki de la colección cortazariana Final del juego listada en el apartado de Bibliografía del presente trabajo.

${ }^{8}$ Cabe citar a Petra Báder, quien ha notado los rasgos de ambigüedad y de omisión en los cuentos de Schweblin: "El uso frecuente de la omisión de referencias da lugar a la ambigüedad, otro rasgo característico de la narrativa schwebliana [...]. En suma, la ambigüedad o lo heterogéneo de los cuentos reside en que el lector debe rellenar con sentido los huecos, estos pozos que Schweblin deja abiertos" (Báder, 2014: 192, 197).

9 "half-woman, half-fish; a divinity of the waters."
} 
La fuerza del orden masculino se descubre en el hecho de que prescinde de cualquier justificación: la visión androcéntrica se impone como neutra y no siente la necesidad de enunciarse en unos discursos capaces de legitimarla. El orden social funciona como una inmensa máquina simbólica que tiende a ratificar la dominación masculina en la que se apoya (Bourdieu, 2000: 22)

Inclusive la antropóloga argentina Rita Segato ha subrayado que el sujeto masculino es "modelo de lo humano y sujeto de enunciación paradigmático de la esfera pública" (Segato, 2016: 20) y que "[1] a historia de los hombres es audible, la historia de las mujeres ha sido cancelada, censurada y perdida en la transición del mundo-aldea a la colonial-modernidad" (Segato, 2016: 26). Por lo tanto, no resulta arbitrario ni insustancial el uso del hombre sirena en el cuento schwebliano: a la vez que dialoga con la tradición simbólico-literaria al resignificar la imagen mitológica, podría interpretarse como una imagen que denuncia y critica el sistema androcéntrico actual de la sociedad que, a su vez, ha perpetuado que dicha imagen se relacionara por antonomasia con la mujer.

Al considerar los planteamientos teóricos citados, la imagen del hombre sirena y su papel axial dentro del relato, interpreto este personaje como una ruptura con la tradición simbólicoliteraria $y$, por extensión, con el sistema androcéntrico que ha dominado el pensamiento, la percepción y las acciones del ser humano actual. Incluso se podría interpretar como una invitación a retar ese sistema, a usar otras imágenes literarias para desafiar lo culturalmente aceptable bajo las estructuras del pensamiento androcéntrico. Probablemente por esta razón es que se aprecian en varios de sus cuentos hombres que no hallan solución a los conflictos que enfrentan o cuya solución les trastoca su visión de mundo perfecta y equilibrada; piénsese en "Pájaros en la boca", "Mariposas" o "La pesada valija de Benavides", entre otros. Estos cuentos de la joven narradora bonaerense pueden leerse como una forma de "desmontar" el sistema patriarcal dentro y fuera del campo literario, pues, según Segato,

mientras no desmontemos el cimiento patriarcal que funda todas las desigualdades y expropiaciones de valor que construyen el edificio de todos los poderes - económico, político, intelectual, artístico, etc.- - mientras no causemos una grieta definitiva en el cristal dura que ha estabilizado desde el principio de los tiempos la prehistoria patriarcal de la humanidad, ningún cambio relevante en la estructura de la sociedad parece ser posible — justamente porque no ha sido posible-. (Segato, 2016: 19-20)

En consecuencia, el texto de Schweblin funge como una de esas grietas en el campo de la literatura. Así, al pensar en los postulados de Agamben sobre el escritor contemporáneo, se advierte que, al emplear la imagen del hombre sirena, Schweblin atañe a un tema de la contemporaneidad: el sistema androcéntrico que se perpetúa en la sociedad y en la tradición literaria. Además, a la vez, dialoga con la tradición simbólico-literaria pasada y propone nuevas formas de pensar la literatura y sus imágenes o símbolos.

Por otro lado, conviene analizar cómo la combinación entre hombre y sirena replantea las categorías de identidad de género del humano, tema que apela a la contemporaneidad desde hace décadas y que continúa teniendo vigencia e importancia en el siglo XXI. Al pensar en los planteamientos teóricos de Judith Butler, se podría considerar que el hombre sirena es un ejemplo de una práctica impensable en la sociedad porque transgrede lo normativo, naturalizado o culturalmente inteligible según la lógica falogocéntrica y binaria del sexo y del género al combinar 
características y acciones que corresponderían a un hombre con otras que se relacionan con las mujeres (Butler, 2016: 9, 25, 28). Como declara Butler,

En la medida en que la "identidad" se preserva mediante los conceptos estabilizadores de sexo, género y sexualidad, la noción misma de "la persona" se pone en duda por la aparición cultural de esos seres con género "incoherente" o "discontinuo" que aparentemente son personas pero que no se corresponden con las normas de género culturalmente inteligibles mediante las cuales se definen las personas. (Butler, 2016: 71-72)

En otras palabras, se entrevé que el hombre sirena es una propuesta nueva a las categorías de género normalizadas o inteligibles para la sociedad falogocéntrica y se replantean dichas categorías de identidad de género con un personaje que combina características tanto de un hombre como de una mujer: "macizo", "musculoso", "canchero", "tiene un jopo muy a lo americano", mas "[t]iene la piel lisa, ni un solo pelo en todo el cuerpo" (Schweblin, 2017: 99-100). Es poco común en Latinoamérica que los hombres se depilen o no tengan ni un solo pelo en el cuerpo, pues como anota Cooper, el pelo es símbolo de virilidad (1978: 77). De hecho, en la sociedad latinoamericana es normal que la mujer sea la que se depile y mantenga su cuerpo libre de vellos, exceptuando el cabello. Este comportamiento se funda en el machismo de la sociedad latinoamericana, pues como expresa Myriam Yvonne Jehenson,

Influida por la herencia hispanoárabe y católico-romana, Latinoamérica ha perpetuado varias tradiciones que han servido exitosamente para marginalizar a las mujeres. Una de estas es el reconocido y diseminado culto al machismo que glorifica al hombre agresivo y sexualmente promiscuo. El segundo fenómeno cultural, igual de potente, es el marianismo. Este, cuyo nombre se origina y refiere a la Virgen María, glorifica el sufrimiento extendido, el sacrificio propio y la castidad y pureza de la mujer, además de la madre dedicada al hogar y su formación. (Jehenson, 1995: 3-4; traducción propia) ${ }^{10}$

Además, sobre esos orígenes machistas Segato ha comentado: "De hecho, el sujeto fundador de las repúblicas de nuestro continente, es decir, el «criollo», no es tal paladín de la democracia y la soberanía como la historia publicita, sino el sujeto de cuatro características que refrendan su exterioridad con relación a la vida: es racista, misógino, homofóbico y especista" (Segato, 2016: 25). No sorprende que las cuatro características destacadas por la antropóloga argentina se hayan perpetuado en la sociedad latinoamericana hasta la actualidad.

El personaje del hombre sirena, por lo tanto, es una imagen que subvierte los límites de género que la sociedad intenta imponer en los seres humanos, pues como menciona Butler,

En realidad, precisamente porque algunos tipos de "identidades de género" no se adaptan a esas reglas de inteligibilidad cultural, dichas identidades se manifiestan únicamente como defectos en el desarrollo o imposibilidades lógicas [...]. No obstante, su insistencia y proliferación otorgan grandes oportunidades para mostrar los límites y los propósitos reguladores de ese campo de

\footnotetext{
10 "Influenced by a Hispanic-Arab, Roman Catholic heritage, Latin America has perpetuated several received traditions that have effectively served to marginalize women. One is the widespread and well-known cult of machismo, which glorifies the aggressive, sexually promiscuous male. The second, equally powerful, cultural phenomenon is that of marianismo. Referring to the Virgin Mary, after whom the practice is named, marianismo, glorifies the long-suffering, self-sacrificing female, pure and chaste, devoted to homemaking and motherhood."
} 
inteligibilidad y, por tanto, para revelar $[\ldots]$ otras matrices diferentes y subversivas de desorden de género. (Butler, 2016: 72-73)

En efecto, la imagen del hombre sirena puede analizarse como una idea que subvierte y replantea las categorías de identidad de género humano a la vez que desafía la tradición androcéntrica del símbolo de la sirena. ${ }^{11}$ Más aún, el relato dialoga con la tradición fantástica hispanoamericana, puesto que no leemos mancuspias o narradores que vomitan conejitos y cuyas implicaciones con respecto a la sociedad no son claras, dado que su innovación literaria se vinculaba más con lo estético que con lo social, sino que crea una metáfora neofantástica que tiene implicaciones directas con la sociedad actual, su mundo y la forma en que se vive en él. Precisamente considero que Schweblin, al romper con ese canon masculino de literatura fantástica hispanoamericana, se inscribe en otra tradición de igual o mayor importancia liderada por mujeres y que desde el siglo XX ha reconfigurado la visión del género literario en cuestión dentro de Latinoamérica. No pasan inadvertidos los nombres de escritoras ilustres como María Luisa Bombal, Elena Garro o Silvina Ocampo. ${ }^{12}$ Así, similar a como hicieron algunas de sus precursoras en el siglo pasado, la escritora entrevé en la oscuridad de la contemporaneidad esos destellos de luz que pueden ser estudiados o interpretados como desafíos o "desmontes" a las estructuras androcéntricas y falogocéntricas de la sociedad.

\section{"El hombre sirena" como metáfora neofantástica de la libertad}

Por otra parte, si bien la imagen del hombre sirena tiene unas implicaciones en relación con la vida contemporánea como se demostró antes, cabría interpretar un posible tenor de la metáfora neofantástica con la información que proporciona el relato acerca de la narradora y de Daniel, su hermano. Desde los inicios del cuento se nota que el conflicto no figura en la metáfora neofantástica del hombre sirena, ${ }^{13}$ sino en la relación con su hermano: "Mi primer impulso es pararme, pero sé que el Tano, el dueño del bar, es amigo de Daniel, y me vigila desde la barra [...]. El Tano se acerca para ver que todo esté bien, insiste en que Daniel ya debe estar por llegar, que debo esperar. Le digo que se quede tranquilo, que enseguida vuelvo" (Schweblin, 2017: 99). Se observa desde el

\footnotetext{
${ }^{11}$ Conviene citar a Rossana Jimena Reyes Cortés, quien ha dicho que los cuerpos abyectos vislumbran "que el engranaje del orden impuesto como natural es sumamente endeble, así, estos cuerpos instalan tiempos de crisis y cuestionamiento, así en la narrativa y así en los discursos disidentes respecto al feminismo actual" (Reyes Cortés, 2018: 19). Coincido con el pensamiento de la crítica, mas añado otros cuerpos como el del hombre sirena el cual, más que abyecto, resulta incoherente según los parámetros de la sociedad falogocentrista o androcentrista.

12 El lector interesado puede considerar el ensayo de Brigitta Kontros titulado "El efecto de incertidumbre en «Olingiris», «La culpa es de los tlaxcaltecas» $\mathrm{y}$ «El árbol»", cuya referencia se encuentra en la bibliografía del presente artículo.

${ }^{13}$ Cabe mencionar nuevamente que en el cuento neofantástico se parte de la premisa de que esos seres o eventos insólitos existen en el mundo descrito porque son parte de una realidad que los admite sin negar sus leyes lógicocientíficas; el elemento neofantástico es parte de esa realidad y funge como una metáfora de "algo" que los lectores deben interpretar. Esto a diferencia del cuento fantástico según lo explica Tzvetan Todorov (2011: 32), en el que se dudaría de la existencia del hombre sirena y se cuestionaría si las leyes del mundo dentro del relato pertenecen al género de lo extraño (la narradora está loca y lo que observa es parte de su locura) o si pertenecen al de lo maravilloso (el hombre sirena y otras criaturas maravillosas existen porque las leyes que rigen ese mundo son mágicas).
} 
principio que hay una intención clara por parte de Daniel y su amigo en vigilar a la narradora; velar que no salga del bar hasta que el hermano llegue. Una vez la mujer está conversando con el hombre sirena, el lector nota que, más que la enfermedad de la madre de quien los médicos creen que no aguantará mucho más, el conflicto de la narradora gira en torno a la forma obsesiva en como Daniel vigila a su hermana: "-Pero ese no es el problema — digo_- el que me preocupa es Daniel. Daniel está mal y eso no ayuda” (Schweblin, 2017: 100). Luego se entrevé dentro de la conversación lo obsesivo que es Daniel con su hermana:

-Está todo el día pensando de dónde va a sacar dinero para pagar esto, de dónde para lo otro. Todo el tiempo queriendo saber qué estoy haciendo, dónde voy a estar, con quién...

- ¿Vive con tu madre?

-No. Mamá es como yo, somos mujeres independientes y necesitamos nuestro espacio. Él considera que es peligroso que yo viva sola. Así nomás me lo dice: "Yo creo que es peligroso que una chica como vos viva sola". Quiere pagarle a una mujer para que esté todo el día detrás de mí. Por supuesto que nunca acepté.

$[\ldots]$

- Me alquila una casita a unas cuadras: cree que este barrio es mucho más seguro. Y se hace amigos por acá, habla con los vecinos, con el Tano, quiere saber todo, controlar todo, es realmente insoportable.

- Mi padre era así.

—Sí, pero él no es mi papá. Papá está muerto, ¿por qué tengo que soportar un papá-hermano si papá está muerto?

-Bueno, quizá solo intenta cuidarte.

Me río sarcásticamente, en realidad, el comentario casi arruina mi humor, y creo que él alcanza a darse cuenta. 101-102)

—No, no. No se trata de cuidarme, es más complicado de lo que pensás. (Schweblin, 2017:

Conviene aclarar que las omisiones que circundan la relación de la narradora con el hermano se han interpretado anteriormente por otros críticos quienes arguyen que la narradora está loca como la madre y que oculta su condición de salud proyectándola en el hombre sirena. Esta interpretación utiliza como base la explicación de la enfermedad de la madre: "Ella no solo está enferma: la verdad es que la pobre está totalmente loca..." (Schweblin, 2017: 102), y lo que Daniel le dice cuando va a recogerla: "Vamos, es tarde. El médico va a matarnos" (Schweblin, 2017: 103). Sobre esta posible interpretación se impone citar a Petra Báder quien ha señalado que "Una de las vías de huida posibles [en el tomo Pájaros en la boca] es la depresión o locura; el cuento titulado «El hombre sirena» nos sirve de ejemplo: la protagonista prefiere escaparse de su mundo por la creación de una proyección mental — un hombre sirena - que a la vez quiebra el curso de $s u$ realidad" (Báder, 2014: 192). Por otro lado, Paula G. Garrido argumenta que "Y es sino hasta el final del relato que entendemos que Daniel está pendiente de su hermana porque ella es esquizofrénica, y que el hombre sirena es en realidad parte de su imaginación" (Garrido, 2014: 178).

Sin embargo, conviene rememorar que la metáfora neofantástica admite diversos tenores, aunque ninguno unívoco; por tal razón, propongo otra interpretación viable al tenor de la metáfora neofantástica del hombre sirena. Considero al hombre sirena como metáfora del deseo de libertad 
que quiere la hermana, de su anhelo por vivir sin estar siendo vigilada en todo momento por Daniel. Al analizar el cuento mediante esta interpretación, la cita en bloque anterior se lee desde una lente distinta: la narradora es como su madre, ambas son independientes y necesitan su espacio. Por lo tanto, son mujeres que atentan contra la dominación masculina o el orden androcéntrico en donde el hombre maneja y controla a la mujer como Daniel quiere hacer con su hermana. ${ }^{14}$ Por tal razón que Daniel quiera saber siempre qué está haciendo su hermana, dónde y con quién. Inclusive, cuando el hermano le dice que es peligroso que ella viva sola, subrayando "una chica como ella", no sugiere una condición de salud como la de la madre, sino a que es una mujer que anhela su libertad de la dominación masculina, una chica que prefiere su independencia. Una vez se reconoce esta interpretación, entonces otras partes de la conversación entre la mujer y el hombre sirena cobran otro sentido, por ejemplo, que Daniel le haya conseguido el sitio donde su hermana vive, que les pida a los vecinos y al dueño del bar que la vigilen, entre otras cosas. La narradora misma expresa lo que cualquier mujer independiente sentiría: "es realmente insoportable" (Schweblin, 2017: 101).

Incluso si se reflexiona en cuanto a la tradición patriarcal de ciertas sociedades, entonces uno comprende que, muerto el padre de la narradora, es el hermano quien debe sustituirlo, quien debe controlar o velar el comportamiento de las mujeres que componen su núcleo familiar. De ahí que la protagonista le comente al hombre sirena que no se trata de cuidarla, sino que es más complicado de lo que él piensa. ${ }^{15}$ Por tal razón, no es poco razonado interpretar al hombre sirena como metáfora de la libertad que la narradora desea. Es otro posible tenor que responde a esa metáfora neofantástica. De hecho, si se interpreta el deseo de libertad como tenor a la metáfora del hombre sirena, se entiende que la narradora sienta una felicidad vital junto a ese ser antropomórfico (Schweblin, 2017: 100).

Tan especial es lo que siente la mujer que describe la experiencia junto al hombre sirena como reveladora:

Le doy un beso y siento el frío de su boca despertar cada célula de mi cuerpo [...]. No es solo una sensación, es una experiencia reveladora, porque siento que ya nada puede ser igual. Aunque no puedo decirle que lo amo: no todavía, debe pasar más tiempo, debemos hacer las cosas paso a paso [...]. Pero la decisión está tomada, es irrevocable. Yo, que toda la vida creí que se vive por un único amor, encontré al mío en el muelle, junto al mar, y me toma ahora francamente de la mano, y me mira con sus ojos transparentes y me dice:

—No sufras más, morocha, ya nadie va a hacerte daño. (Schweblin, 2017: 102)

Nadie podrá hacerle daño porque junto al hombre sirena será libre, no estará bajo la vigilancia de su hermano. Además, no resulta extraño que lo ame, pues es amor a la libertad que anhela. Posteriormente, Daniel llega al muelle y busca a su hermana en el bar. El hombre sirena ayuda a la

\footnotetext{
${ }^{14}$ En cuanto al control ejercido sobre la mujer, Bourdieu comenta: “A los que puedan objetar que muchas mujeres han roto actualmente con las normas y las formalidades tradicionales del pudor y verían en el espacio que dejan a la exhibición controlada del cuerpo un indicio de «liberación», basta con indicarles que esa utilización del propio cuerpo permanece evidentemente subordinada al punto de vista masculino" (Bourdieu, 2000: 44); ciertamente la mujer sigue subyugada al control masculino.

${ }^{15}$ Cabe añadir que Jorge Antonio Sánchez Rivera ha comentado que la relación entre estos hermanos podría sugerir un deseo incestuoso o posesivo por parte de Daniel (Sánchez Rivera, 2020: 76).
} 
narradora a bajarse del hormigón y ella va adonde Daniel y demuestra que el haber estado con el hombre sirena fue una experiencia reveladora:

— ¿Dónde estabas? Quedamos en tu casa, no en el bar.

No es cierto, pero no le digo nada, eso no importa ahora.

-Necesito hablarte - digo.

- Vamos al auto, hablamos en el auto.

Me toma del brazo, con delicadeza, pero con esa actitud paternal que tanto me enerva, y salimos. El auto está a unos metros, pero me detengo.

-Soltame.

Me suelta pero sigue hacia el autor y abre la puerta.

- Vamos, es tarde. El médico va a matarnos.

-No voy a ningún lado, Daniel.

Daniel se detiene.

—Voy a quedarme acá —digo—, con el hombre sirena. (Schweblin, 2017: 103)

Se nota un cambio en la forma de ser de la narradora en relación con su hermano. Ella desafía ese orden androcéntrico que la ha subyugado al decirle que se quedará con el hombre sirena. Nuevamente, afirmo que ese elemento neofantástico es la metáfora de su deseo de libertad, por ello que le hable de tal forma a su hermano y que se niega a irse con Daniel al médico. No obstante, al final del relato, la narradora cede ante la orden de su hermano, mas hace un comentario que atañe al ser humano contemporáneo:

Y aun así, Daniel entra al auto y abre la puerta de mi lado. Entonces no sé qué hacer, y cuando no sé qué hacer, el mundo me parece un lugar terrible para alguien como yo, y me siento muy triste. Por eso pienso: es solo un hombre sirena, es solo un hombre sirena, mientras me subo al auto y trato de tranquilizarme. Puede estar ahí otra vez mañana, esperándome. (Schweblin, 2017: 103; énfasis añadido)

Por supuesto, el mundo parece un lugar terrible para alguien como ella, porque es una mujer y su cuerpo está condicionado a estar sumiso ante las directrices del hombre, de la sociedad androcentrista o de la dominación masculina que describe Pierre Bourdieu (2001: 37-38). Aquí cifra la importancia del relato y del análisis para la sociedad contemporánea, pues muestra cómo en la actualidad la mujer aún se encuentra subyugada a la dominación masculina. Al final, la posibilidad de libertad dependa igualmente de un hombre, aunque este sea un hombre sirena. ¿Acaso esa oportunidad de libertad junto a un hombre impele a los lectores a cavilar en cómo el patriarcado continúa perpetuándose en las sociedades latinoamericanas actuales? Cabe citar nuevamente a Rita Segato, quien ha comentado en su libro publicado en 2016: "Permanece aquí, también y a pesar de todo el debate reciente sobre este tema [el género y la violencia], mi convicción de que el patriarcado, o relación de género basada en la desigualdad, es la estructura política más arcaica y permanente de la humanidad" (Segato, 2016: 18; énfasis añadido). En efecto, el cuento schwebliano podría asimismo dirigir al lector atento a reflexionar sobre la perpetuidad de esa estructura arcaica arraigada todavía en el pensamiento de los humanos. De hecho, considero que el cuento no culmina con la liberación de la narradora precisamente porque es una crítica a la dominación masculina y a cómo esta se perpetúa en la sociedad contemporánea. 
En dicha crítica a la persistencia del sistema androcéntrico en la contemporaneidad están los destellos de luz que, según Agamben, se acercan y alejan dentro de la oscuridad del presente y que Schweblin permite entrever mediante la metáfora neofantástica del hombre sirena.

Además de la crítica expuesta, cabe afirmar nuevamente que la autora es contemporánea porque mantiene un diálogo con la tradición literaria de lo fantástico en Hispanoamérica. La diferencia figura en que no es un Aleph o sonidos que se toman una casa o un ente sin nombre que un adolescente lleva al parque, sino una metáfora que apela al ser humano contemporáneo y denuncia el sistema social actual que mantiene a la mujer subyugada a la dominación masculina, al orden androcéntrico o al sistema patriarcal. Schweblin forma parte de las herederas de la tradición fantástica femenina cuyos "desmontes" o grietas al patriarcado también perseveran dentro y fuera del campo literario. Me refiero a escritoras como Armonía Somers, Rosario Ferré o Amparo Dávila, además de las mencionadas en el apartado anterior. Para ejemplificar esa herencia, basta comparar el relato breve "El huésped", de Amparo Dávila, con "En la estepa" o "Conservas" de Schweblin para observar las implicaciones de ambos en relación con la estructura familiar, las imposiciones sociales que subsisten en la actualidad y, sobre todo, la posición subordinada en que se encuentran las mujeres. Son las mismas ideas que repercuten y conciernen al ser humano de hoy.

Así que, en definitiva, en "El hombre sirena" se halla el elemento neofantástico porque "el relato se desliza hacia un destino que no es ni lo fantástico puro ni lo histórico-realista, sino apenas un intersticio por medio del cual el escritor se asoma a sus entrevisiones que, en última instancia, son el verdadero destino hacia el cual enfila el cuento" (Alazraki, 1994: 69). De igual modo, ese elemento le sirve a Schweblin para expresar y profundizar en una situación y unos temas que incumben al presente y al futuro próximo del ser humano y de la sociedad. Conviene remembrar que la metáfora neofantástica, tanto en este como en otros cuentos schweblianos, admite más de un tenor porque elude la interpretación unívoca. Esto permite, a su vez, que su lectura y sus interpretaciones se renueven simultáneamente con el paso del tiempo. En este espacio breve he propuesto otra interpretación a la metáfora del hombre sirena, empero, no es ni será la única interpretación existente, pues la ambigüedad y la falta de univocidad son los componentes principales tanto del texto neofantástico como de la narrativa de Schweblin.

\section{Conclusiones}

Un aspecto queda claro luego de nuestro análisis de lo neofantástico en el cuento "El hombre sirena" y es que el uso de este elemento en la ficción de la joven narradora argentina responde a una necesidad de comprender al ser humano y al mundo contemporáneo. Precisamente, lo que he examinado en el relato schwebliano es el resultado de una escritura y de imágenes cuyos significados dependen del lector, pero que, al final, transmiten temas y problemas del mundo actual. Sin embargo, no puede olvidarse que esos temas y situaciones del presente se encuentran en diálogo constante con su pasado. Como ha declarado Elsa Drucaroff acerca de la generación de la postdictadura, en la que incluye a Schweblin, "Por eso creo que lo que escriben las generaciones de postdictadura tiene un modo propio de mirar el mundo. Un modo que [...] es significativo en el presente y dice cosas acerca de la relación de esta literatura con el pasado argentino" (Drucaroff, 
2011: 24). Ciertamente es lo que se ha visto a través del análisis del texto mencionado: un diálogo con la tradición literaria del género fantástico hispanoamericano y con los símbolos canónicos de la literatura. Además, como declara Reyes Cortés, "La escritura, en este sentido, [...] [hace] visible aquello que sí está presente ante nuestros ojos y que no queremos ver, aquello que nos incomoda percibir" (Reyes Cortés, 2018: 49). En este caso, lo que nos incomoda percibir es cómo la sociedad androcéntrica o la dominación masculina sigue perpetuándose en esta segunda década del nuevo milenio. En última instancia, considero que Samanta Schweblin es una autora contemporánea porque ella "no es sólo aquel que, percibiendo la oscuridad del presente, aferra su luz que no llega a destino; es también quien, dividiendo e interpolando el tiempo, está en condiciones de transformarlo y ponerlo en relación con otros tiempos" (Agamben, 2011: 28). De esa relación temporal y de su obra narrativa se desprenden las reflexiones o los planteamientos que provocan en los lectores el deseo de un mundo y una sociedad disímil a la impuesta desde la época colonial.

\section{Bibliografía:}

AGAMBEN, Giorgio (2011): “QQué es lo contemporáneo?”. Trad. Cristina Sardoy. Desnudez. Buenos Aires, Adriana Hidalgo editoria: 17-29.

ALAZRAKI, Jaime (1983): En busca del unicornio: los cuentos de Julio Cortázar. Elementos para una poética de lo neofantástico. Madrid, Gredos.

--- (1994): Hacia Cortázar: aproximaciones a su obra. Barcelona, Anthropos.

--- (1999): Critical Essays on Julio Cortázar. New York, G. K. Hall \& Co.

--- (2010): “La narrativa fantástica: Jorge Luis Borges, Felisberto Hernández y Julio Cortázar”. En Dario Puccini-Saúl Yurkievich (eds.): Historia de la cultura literaria en Hispanoamérica II. México, Fondo de Cultura Económica: 785-832.

BÁDER, Petra (2014): "Locura, elipsis y tergiversación de la realidad: Pájaros en la boca de Samanta Schweblin”. Verbum Analecta Neolatina, XV/1-2: 191-197.

BOURDIEU, Pierre (2000): Dominación masculina. Trad. Joaquín Jordá. Barcelona, Anagrama.

BUTLER, Judith (2016): El género en disputa. El feminismo y la subversión de la identidad. Trad. María Antonia Muñoz. Barcelona, Paidós.

CIRLOT, Juan Eduardo (1992): Diccionario de símbolos. Barcelona: Editorial Labor.

COOPER, Jean C. (1978): An Illustrated Encyclopaedia of Traditional Symbols. New York, Thames \& Hudson.

CORTÁZAR, Julio (1995): Final del juego. Ed. Jaime Alazraki. Madrid: Anaya-Mario Muchnik.

DRUCAROFF, Elsa (2011): Los prisioneros de la torre. Política, relatos y jóvenes en la postdictadura. Buenos Aires, Emecé.

GALLEGO CUIÑAS, Ana (2018): "Las narrativas del siglo XXI en el Cono Sur: estéticas alternativas, mediadores independientes". Ínsula: Revista de Ciencias y Letras Humanas, 859-860: 8-12. 
--- (2020): "Feminismo y literatura (argentina) mundial: Selva Almada, Mariana Enríquez y Samanta Schweblin". En Gustavo Guerrero-Jorge L. Locane-Benjamin Loy_Gesine Müller (eds.): Literatura latinoamericana mundial. Dispositivos y disidencias. Berlin, De Gruyter: 71-96. DOI: https://doi.org/10.1515/9783110673678-006

GARCIA, Flavio (2016): “«Na estepe», de Samanta Schweblin: Um exemplo de fantástico contemporâneo, na sequência do cânone consagrado por Cortázar". ALEA: Estudios Neolatinos, XVIII/1: 65-80. DOI: https://doi.org/10.1590/1517-106X/181-65

GARRIDO, Paula C. (2014): Las formas de lo irreal en la cuentística de seis escritoras argentinas contemporáneas: Luisa Axpe, Liliana Díaz Mindurry, Fernanda García Curten, Paola Kaufmann, Mariana Enríquez y Samanta Schweblin. Michigan, ProQuest.

JEHENSON, Myriam Yvonne (1995): Latin-American Women Writers: Class, Race, and Gender. New York: State University of New York Press.

KONTROS, Brigitta (2019): "El efecto de incertidumbre en «Olingiris», «La culpa es de los tlaxcaltecas» y «El árbol»: Un estudio comparativo de tres relatos breves hispanoamericanos". Tesina. Göteborg, Göteborgs Universitet.

LIVELLARA ABRILE, Julia (2019): "La poética de lo fantástico y su modulación en Pájaros en la boca de Samanta Schweblin". Tropelías. Revista de Teoría de la Literatura y Literatura Comparada, 31: 341-358. DOI: https://doi.org/10.26754/ojs_tropelias/tropelias.2019313156

PRADO ALVARADO, Agustín (2017): "Presentación. Nuevos cuentos para el nuevo siglo XXI". América sin Nombre, 22: 13-15. DOI: https://doi.org/10.14198/AMESN.2017.22.00

REYES CORTÉS, Rossana Jimena (2018): Cuerpos monstruosos y escrituras abyectas, una revisión de la narrativa de Mariana Enríquez y Samanta Schweblin. Tesina. Santiago de Chile, Universidad de Chile.

SÁNCHEZ RIVERA, Jorge Antonio (2018): “Animales neofantásticos: Paralelismos entre «Después del almuerzo» de Julio Cortázar y «Pájaros en la boca» de Samanta Schweblin”. En Rosana Hernández-Francisco Moreno-Fernández (eds.): Reshaping Hispanic Cultures. Instituto Cervantes Symposium on Recent Scholarship, vol. I: "Literature". Cambridge, Harvard University: 109-120. DOI: https://doi.org/10.15427/OR03903/2018SP

--- (2020): Elementos neofantásticos en la obra narrativa breve de Julio Cortázar y Samanta Schweblin. Tesina. Michigan, ProQuest.

SCHWEBLIN, Samanta (2017): Pájaros en la boca y otros cuentos. Barcelona, Penguin Random House Grupo Editorial.

SEGATO, Rita Laura (2016): La guerra contra las mujeres. Madrid, Traficantes de Sueños.

TODOROV, Tzvetan (2011): Introducción a la literatura fantástica. Trad. Elvio Gandolfo. Buenos Aires, Paidós.

(C) Jorge Antonio Sánchez Rivera 


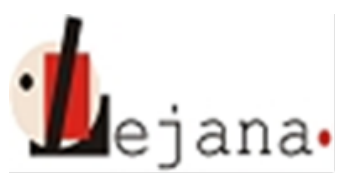

http://ojs.elte.hu/index.php/lejana

Universidad Eötvös Loránd, Departamento de Español, 1088 Budapest, Múzeum krt. 4/C 